\title{
The Construction of "Double First-Class" against the Background of New Era - A Case Study of Zhongnan University of Economics and Law
}

\author{
Wei LIU \\ Planning Ministry, Zhongnan University of Economics and Law, Wuhan, China. \\ Distinct addresses: 182\# Nanhu Avenue, Wuhan 430073, P.R. China \\ E-mail:liuewei@foxmail.com
}

Keywords: Double First-Class, New Era, Discipline.

\begin{abstract}
Double First-Class" construction is a leap in our country from a high power of higher education to a power higher education in a new era. It is a major opportunity to the development of the Universities. Universities also face many difficulties. We should make great efforts to build up teachers, institutions and funds.
\end{abstract}

\section{Introduction}

On August 18, 2015, the Central Committee's leading Group for All-round deepening Reform deliberated on the adoption of the "overall Plan for promoting the Construction of the World's First-class Universities and Topics," and made a new plan for the key construction of higher education in the new period. The key construction projects, such as "211 Project"'Project 985" and "platform for Innovation of advantage disciplines", were uniformly incorporated into the construction of world-class universities and disciplines, which were issued and issued by the State Council in November of the same year. In January 2017, with the consent of the State Council, the Ministry of Education, the Ministry of Finance, the National Development and Reform Commission issued "measures for the implementation of the Construction of first-class Universities and first-class disciplines (provisional)."

On 21 September 2017, the Ministry of Education, Ministry of Finance, The State Development and Reform Commission jointly issued the Circular on promulgating the list of world-class universities and first-rate discipline construction colleges and construction disciplines, and officially confirmed the publication of the list of world-class universities and first-rate discipline construction institutions and disciplines. The first batch of double first-class construction colleges and universities total 137, of which 42 are world first class universities, 36 are A type and B class 6, 95 are world first class subjects, and 465 are double first-class construction subjects (of which 44 are self-determined subjects).Among them, our university's law discipline was successfully selected as "double-class". Under the background of the new era, how to build "double first-class"? This article discusses the great significance of "double First-class" to our country and universities, and takes our university as an example, discusses the difficulties and key points of double-first-class construction.

\section{"Double First-Class" Construction Is a Leap in Our Country from a High Power of Higher Education to a Power Higher Education in a New Era}

The rise and fall of a university is closely related to the rise and fall of a great nation. Where the rise of first-class universities, where there is a rise of a nation, a nation's prosperity. Discipline is the most basic element of a university. World-class universities are based on many world-class disciplines. For example, the oldest university, the founding and flourishing of the University of Bologna, Italy, originated from the renaissance of Roman law. Therefore, the "double first-class" construction is based on the construction of first-rate disciplines to promote the construction of first-class universities. Reviewing the history of higher education and the development of disciplines in China, over the years, the construction of a number of key universities, especially key disciplines, has led to an overall improvement in the level of higher education in China. In the early 
1980s, colleges and universities focused on the construction of master's programs. After the mid-1980s, the focus of discipline construction shifted to the construction of doctoral programs. Since the 1990s, especially since the beginning of the new century, through the construction of the first-level key disciplines, the "211 Project" and the "985 Project," the discipline construction has advanced a few further steps. The history of subject construction reflects the history of the continuous development and rapid improvement of China's higher education, and it is also a history of China's socialist modernization that has made great achievements.

Since the 18th National Party Congress, a comprehensive, deep-rooted and fundamental reform has taken place in the party and state undertakings, and socialism with Chinese characteristics has entered a new era."Double First-Class" construction will promote a group of high-level universities and disciplines to enter the world in a popular or forefront, It is a major strategic decision made by the Party Central Committee and the State Council, and it is a new strategic plan based on the law of discipline development and the development of higher education. It is a historical leap from China's higher education to a strong country in higher education in the context of the new era. It is also a major project of higher education after the " 211 ” and “985” projects.

\section{"Double First-Class" Construction is a Major Opportunity to the development of the Universities}

Creating a world-class university is the dream and pursuit of several generations of China.90 years ago, Mr. Chen Jun took the opportunity of celebrating the 20th anniversary of Tsinghua University to point out the rise and fall of the academic field. "It is a matter of life and death in our nation."Since the reform and opening up, we have thoroughly studied the West and gradually integrated into the globalization system, realizing the tremendous accumulation of materials and the remarkable leap in academic disciplines. The vivid practice of the great rejuvenation of the Chinese nation provides a rich practical soil for the construction of Chinese disciplines, academics and universities, as well as an unprecedented historic opportunity.

In May 2017, the CPC Central Committee stressed in its opinion on speeding up the Construction of philosophy and Social Sciences with Chinese characteristics that "to uphold and develop socialism with Chinese characteristics, we must accelerate the construction of philosophical and social sciences with Chinese characteristics."Chinese Dream provides strong ideological and theoretical support for achieving the goal of "two hundred years" and realizing the great rejuvenation of the Chinese nation. In September 2017, in "opinions on deepening the Reform of the Educational system and Mechanism", the CPC Central Committee further proposed "increasing the support for the research of philosophy and social sciences, and perfecting the discipline system, academic system, and discourse system of philosophy and social science with Chinese characteristics, "Construct the academic standard and academic evaluation system with Chinese characteristics."

For the universities of humanities and social sciences, the historical mission of "double first-class" construction is to form a knowledge system with Chinese characteristics and solve Chinese problems, and to contribute Chinese wisdom to the world and to provide a Chinese plan. It has made great contribution to the national economic development and the construction of the rule of law by quickly and in large quantities cultivating the style and orientation of the talents in urgent need of reality. The development of the universities has always depended on the same roots and complementary advantages of finance and politics and law. The history of universities development is always in line with national development and social progress, synchronous, peer, witness, participate in the inheritance of higher education in China, stick to and flourish. After nearly 70 years of construction, the comprehensive strength of the university has been significantly improved, the discipline layout has been continuously improved, and the overall strength of the discipline has been continuously enhanced. In 2005 and 2011, the universities entered the ranks of "211" project and "985advantage discipline innovation platform". The selection of the first-class discipline construction university, is recognized for our history, discipline characteristics and achievements .

The construction of first-class discipline is a great strategic opportunity for the development of 
our universities, as well as our historical mission and time responsibility. We must firmly grasp the choice of this era, base ourselves on the ground of China, adhere to the Chinese characteristics, aim at the first class in the world, condense the direction of the discipline, build the peak of the discipline, and base on the Chinese theory. China's practice leads the international frontier of legal and economic research, and puts forward the "Zhongnan" scheme for promoting world development and the progress of human civilization.

\section{Challenges Faced by the Construction of First-class Disciplines}

The first - class discipline construction has opened a new chapter . We have accumulated , confident and actively promoted the first - class discipline construction , and also deeply realize the serious and arduous task of the situation . In combination with the current situation of the construction of discipline construction , the first - class discipline construction in our university faces the following challenges :

\section{Dynamic Adjustment and Fierce Competition}

The construction of "double first-class" emphasizes more encouragement, restraint and fair competition, strengthens the goal management and highlights the construction performance. Adopt the dynamic evaluation method of "five-year rolling", break the identity solidification. In the face of "double-class" dynamic adjustment in 2020, it can be described as fierce competition, slow progress and retreat.

\section{It is Difficult to Condense Consensus}

With the advancement of the first-class discipline construction and the profound adjustment of interest pattern, it is difficult to condense the consensus of reform. Different disciplines, colleges and institutions will have different understandings and construction ideas, key points of construction and resource allocation, and the task of taking into account the interests of all sides is arduous.

\section{High Level Talented Person, the Total Quantity of Achievement is Insufficient}

In the fourth round of discipline evaluation, the number of high-level talents in our university has obviously improved compared with the previous two rounds, but there is a big gap between the number of academic leaders and the similar colleges. The scientific research results of high quality and high display degree are less. Per capital scientific research projects are not commensurate with the scale of teachers. The overall level of scientific research is quite different from that of the world's first-class universities, and it has no obvious advantages compared with the similar universities in China, and faced with enormous competitive pressure.

\section{The System and Mechanism of Discipline Construction Need to be Improved}

First, the subject layout needs to be optimized. First-rate discipline evaluation is carried out by first-level discipline. Due to the system and history, most of our colleges are based on the second-level discipline at present. The system of department structure and resource allocation based on secondary disciplines is not conducive to the integration of resources and affects the overall development of first-level disciplines. In addition, there are gaps in the setting of some subject points.

Second, discipline construction management system needs to be improved. The construction of first-class disciplines requires the cooperation of various functional departments and departments to enhance the efficiency of communication, coordination and problem-solving, to eliminate the constraints on the development of first-class disciplines, to form a joint force, and to realize the development of the discipline "breaking rules".

In addition, in the first-class discipline construction performance evaluation and resource allocation, further efforts should be made to improve the institutional mechanism. 


\section{Main Measures to Promote the Construction of First-class disciplines}

Focusing on the short-term goal of 2020, the promotion of the university's first-class discipline construction mainly starts from the following aspects:

\section{Gather Consensus and Create a Good Atmosphere for the Construction of First-class Disciplines}

The first-class discipline construction plan is a programmatic document to guide and standardize the first-class discipline construction, through learning, seminars and other forms of communication, in-depth study of the basic content of the construction project, a deep understanding of the university target positioning and strategic deployment, widely recognized the greatest degree of seeking teachers and students. Firmly establish crisis awareness, awareness of suffering, scientific response to the competition and challenges faced by the universities. Widely publicize the reputation of the discipline, expand the influence, attract the majority of alumni and social forces to further concern and support the first-class discipline construction, create a good social environment and public opinion atmosphere.

\section{Make Clear the Task and Establish the Mechanism of Decomposition and Implementation of the Construction Plan}

The comprehensive promotion of the first-class discipline construction and the examination and acceptance of the Ministry of Education in the future are guided by the first-class discipline construction scheme. Each construction unit shall decompose the tasks of the construction objectives of the construction plan, scientifically formulate its own construction plan and annual construction plan, and make clear the time arrangement for the implementation of the construction task and the main body of responsibility in light of its own reality, Supporting measures and construction quality standards. Riveting the responsibilities of all parties and conducting layers of pressure to make the plan clear, accurate and efficient. Regularly compile first-class discipline construction bulletin, timely adjust and correct problems to ensure construction process and construction quality.

\section{Breaking down Barriers and Adjusting the Distribution of Disciplines}

From the strategic height of improving the overall competitiveness of disciplines, breaking down the long-existing barriers between disciplines and faculties, adjusting the layout of disciplines, highlighting the key points of discipline construction, condensing the direction of discipline development, advocating cross-integration, and filling up the blank of discipline construction, Build a discipline system that meets the needs of the development of first-class disciplines.

\section{Gather Resources and Focus on Building leading Disciplines}

Proceeding from the overall situation of the development of the university, we should increase the reform of the mode of allocation of discipline resources, promote the resources of the whole university to gather in the leading disciplines, focus on investment, focus on the construction of law and applied economics, and comprehensively improve the level and quality of the two leading disciplines. Take the lead in attacking the world class.

\section{Strengthening Construction of the Dominant Discipline}

We will strengthen the construction of superior disciplines and support disciplines. Focusing on the major strategic needs of the country, focusing on the forefront of science and technology in the world, actively promoting the cross-integration with the first-class construction disciplines, the cross-merging of the first-class construction disciplines and other disciplines, and vigorously fostering the emerging disciplines and interdisciplinary disciplines to improve and support each other, distinctive characteristics, common development of the benign discipline ecological system.

\section{Cooperating and Innovating, Perfecting the Management System of Discipline Construction}

We will further give full play to the advisory role of the first-class discipline construction steering 
committee in discipline construction. We should further strengthen the sense of coordination of the executive committee of discipline construction at the level of "overall situation and overall consideration", and strengthen the power and responsibility in the allocation of discipline resources.

\section{Release Potential and Strengthen Incentive and Restraint Mechanism of Discipline Construction}

We will deepen the project management system for discipline construction funds. We should push forward the dynamic mechanism of the combination of discipline performance evaluation and discipline resource allocation, break the discipline solidification through the dynamic performance management of the project, and further improve the utilization benefit of the first-rate discipline construction funds. As soon as possible, we will issue a first-rate discipline construction award plan, take the fine goods as the guide, substantially increase the reward intensity for the first-class discipline construction achievements with high display, fully mobilize the enthusiasm of the organizations and individuals, and enhance the endogenous development motive force. To promote the production of high level academic achievements, to build a more scientific and reasonable evaluation system, strengthen the evaluation of teachers, and improve the scientific research outputs.

\section{References}

[1] Chen yinque: The present situation of our country's academic and the duty of Tsinghua, Jinming Guildhall's second edition of manuscripts, Triple bookstore, Beijing, 2002, PP361-363.

[2] http://www.gov.cn/xinwen/2017-05/16/content_5194467.html

[3] http://www.moe.edu.cn/jyb_xwfb/gzdt_gzdt/201709/t20170925_315201.html 